sufficient to prevent softening of glands, even when it is continued for more than a year. Originally streptomycin and P.A.S. were used, and later I.N.H. and P.A.S. The latter combination can be given for long periods without difficulty. The effect of giving chemotherapy to children with firm glands recently infected is interesting, there is an immediate response which is proportional to the original size of the glands. Thus in a febrile child with an acute reaction, and a large mass of glands with much peridenitis, the temperature falls rapidly, and the swelling shrinks, often resolving into two or more discrete glands. In a child with a small gland and little change in general health or bodily reaction the change is correspondingly less. But all children improve in health and well-being and all recently infected glands show some reduction in size when first treated. This improvement continues for about three to four weeks and then stops, leaving a firm, movable, painless gland. If the chemotherapy is continued, the gland may remain in this state for many months but those we have observed have softened ultimately. Once softening occurs, skin involvement is inevitable and then the chance of achieving a good cosmetic result has largely gone.

In looking after a child with recent tuberculous infection of glands I therefore use chemotherapy and continue as long as necessary until the first sign of secondary enlargement of the gland occurs. Then I advise removal of the whole gland and its immediate neighbours by careful local dissection. No attempt is made to remove all infected glands, for infection has spread far down the lymphatic chain, but great care is taken with the final suturing of the wound. Chemotherapy is continued for at least a year after the infection. The prolonged chemotherapy has two purposes: to help to avoid further local abscesses and to prevent haematogenous lesions in other organs. Chemotherapy is just as necessary when the lymph glands are superficial and visible as it is when the infection is pulmonary or mesenteric.

Streptomycin ( $45 \mathrm{mg}$. per kilo, $20 \mathrm{mg}$. per I lb. body weight, with a maximum dose of $\mathrm{I}$ g. per day) and I.N.H. (20 mg. per kilo, maximum $400 \mathrm{mg}$.) are used to cover the operation and until the wound is firmly healed. The daily injection of streptomycin is then stopped and P.A.S. (125 mg. per I lb., $300 \mathrm{mg}$. per kilo) is given instead and continued for at least a year.

If the glands are soft when first seen, the situation is not so favourable, but, whether infection is recent or old, the general problem is the same and chemotherapy should be given as described above. When there is calcium present and infection has been present for a considerable time there is not the same risk of new haematogenous spread but I.N.H. and P.A.S. should be given for six months.

The basic trouble when the gland has softened is that it cannot be removed as a whole, and if caseous material is left at the site of the abscess then there is always a risk of subsequent abscess formation. Unless the contents of the gland are exceptionally fluid, mere incision is not likely to remove all caseous material; for this reason other methods, such as curettage or expression, have been used, and more recently Lincoln (1957) has used enzyme irrigation to achieve the same purpose. If the caseous material can be removed healing will follow, but the final appearance of the scar depends upon the amount of skin loss.

The early recognition and effective treatment o tuberculous lymphadenitis in this way can reduce the length of illness, the chance of complications and avoid the pigmented scars seen a generation ago.

In conclusion, therefore, it can be seen that the situation with regard to peripheral tuberculous lymphadenitis is changing rapidly, new cases are becoming less and less common as the sources of infection are brought under control, but old cases infected some time ago continue to present for treatment. Peripheral tuberculous lymphadenitis is also still to be seen in adults but, as I indicated at the beginning of this paper, its natural history seems different from that of tuberculous adenitis in childhood and it may require different treatment.

\section{BIBLIOGRAPHY}

ANASTASIADES, A. A., TSIKOUDAS, E. C., LINCOLN,

E. M., and DALY, J. F. (1957), Amer. Rev. Tuberc., 76, 588 . MILLER, F. J. W., and CASHMAN, J. M. (1955), Lancet, i, 1286. MILLER, F. J. W., and CASHMAN, J M. (1958), Ibid.,

MILLER, F. J. W. (1953), Ibid., i, 3.

SMITH, C. M. (1958), Med. Offr., 99, 45.

\title{
Erratum May Issue
}

We apologize for the illustration appearing in Dr. J. D. H. Slater's article on 'Oral Hypoglycaemic Drugs' which we regret was included in error. 